\title{
COMMENTS
}

\section{Hymen interrupted: Negotiating body, markets, and consumerist modernity in India}

\author{
TANNISTHA SAMANTA
}

\begin{abstract}
In this commentary, I contend that in a context marked by a slow but steady rise in sexual liberalism around the ideals of female sexuality and desire, the pressure to remain virginal is manifested through a potent nexus of markets and moral economies associated with gender and intimacy. Drawing on qualitative interviews with surgeons specialising in female genital aesthetic surgeries, particularly hymenoplasty, in New Delhi, Ahmedabad, and Bangalore, I show how restorative cosmetic surgeries on healthy bodies are proffered through the language of duty, autonomous choice, and the (neoliberal) market. Further, building on the sociological concepts of "moral consumption" and "progress through pleasure", I show how consumerism-led modernity makes pleasure a 'biopolitical burden', and the cosmetic industry, a regulatory vehicle, disciplining female sexuality to conform with male honour codes. I question what this holds for the sexual and reproductive health politics of young people in India, in a context marked by pervasive asymmetries of socialisation, gender relations, and sexual experience. I conclude with a call to unsettle the social-moral ideals around female sexuality and to rethink the medical-legal frameworks around the cosmetic industry so that young people are not unwittingly co-opted into its production of ideal, patriarchal subjects.
\end{abstract}

Keywords: Hymenoplasty; moral consumption; desire; India

\section{Introduction}

In many cultures, including India, female virginity is often associated with chastity, purity, and sexual respectability and is capable of shoring up individual and family honour. Indeed, female virginity works as a "social category" (1) that leads to social relations being forged or abandoned. This social meaning-making around female virginity assumes remarkable significance in (arranged) marriages in India, where appropriate parental approvals and social sanctions are common. In this piece, I contend that given the slow but

\footnotetext{
Author: Tannistha Samanta (tannistha.samanta@flame.edu.in), Associate Professor, Department of Sociology, School of Liberal Education, FLAME University, Pune - 412115, Maharashtra, India

To cite: Samanta T. Hymen interrupted: Negotiating body, markets and consumerist modernity in India. Indian J Med Ethics. 2021 Apr-Jun; 6(2) NS: 163-169.DOI: 10.20529/IJME.2021.001.

Published online first on January 4, 2021.

Manuscript Editor: Nikhil Govind

Peer reviewers: Ketaki Chowkhani and an anonymous reviewer

(c) Indian Journal of Medical Ethics 2021
}

steady rise in sexual liberalism around female sexuality, desire, and pleasure (2-6), the pressure to remain virginal is manifested through a potent nexus of markets and moral economies associated with gender and intimacy. Drawing on interviews with surgeons specialising in female genital aesthetic surgeries in New Delhi, Ahmedabad, and Bangalore, I show how restorative surgeries on the healthy body are proffered through the language of sexual "rights" and the (neoliberal) market. I reflect on how questions of respectability, marriage anxieties, and notions of desirable modernity shape this discourse by inviting young women into their own production as ideal patriarchal subjects.

Ultimately, the larger question posed through these interrogations is: how are we to make sense of the sexual freedoms of women in the age of "moral consumption" (7: p. $341,8)$, in which the paradigms of tradition and modernity have been harmoniously fused? Subsequently, how do standard models of sexual and reproductive health (SRH) research respond to these shifting realities in the global South? Notwithstanding the recent calls $(9,10)$ to address the "unfinished agenda for sexual and reproductive health in the Sustainable Development Goal (SDG) era" (11: p 6), and the need to transcend traditional approaches that emphasise family planning and HIV prevention, ${ }^{i}$ it is surprising that the often uneasy alliance of technology and markets with young people's sexual lives still remains outside the ambit of these renewed discussions. Given that young people in the global South will increasingly form the consumer base for medical products and services, this neglect is problematic.

Family sociologists and anthropologists conducting research on India have noted a shift in how modern intimacies are perceived using the idioms of choice, companionship, and emotional compatibility $(12,13)$. Despite these putative changes, scholars have argued that the moral economy (14) of the family remains centred on governing the premarital and conjugal intimate practices of young Indians $(5,6)$. For example, Bhandari's (5) ethnographic study on professional young adults in premarital relationships in New Delhi showed how young women experience more social surveillance and are expected to exercise greater self-control of their sexual selves than men in similar relationships. The author noted that despite the modern self-making achieved through individuated erotic love in these premarital relationships, the Hindu ritual of kanyadaan (gift of a virgin) governs the suitability and prospects of young women in arranged marriages.

Twamley and Sidharth (6) echoed similar sentiments in their work on young women in a Mumbai slum and in the small town of Baroda (in the western state of Gujarat), where 
women in premarital relationships routinely engaged in selfsurveillance "strategies" such as dressing appropriately, going on "respectable" outings with their male partners, and keeping outdoor socialising times in line with their parents' expectations. Significantly, the authors note that these "strategies" of young women are prevalent across all classes and castes, pointing to the hegemonic cultural significance of feminine respectability. This pressure to appear sexually respectable also influences conjugal intimacies, as Puri (2) reports, based on her interviews with urban married women, whose accounts portray sex as a wifely duty performed for the "understanding" husband; Puri aptly labels this as the "marital romanticisation of sex" (2: p 119). Taken together, in these "modern" articulations of intimacy, the notion of sexual respectability is firmly lodged in and understood through a woman's sexual comportment and her virginity, or, as Phadke (15) sharply puts it in her description of middle-class sexuality in neo-capitalist India, a woman must be "sexy, but respectable" (15: p. 72).

Building on this scholarship, I contend that feminist scholarship on desire and sexuality can be rendered more fruitful by engaging with the "market", which, as I show by using the case of aesthetic procedures, simultaneously enables (female) sexual autonomy while reinforcing asymmetries of socialisation, gender relations, and sexual experience.

\section{The virginity industry: gender, body, and technology}

The neoliberal restructuring of the Indian economy that started in the 1990s transformed healthcare from a public sector to one that is a site of corporate profitmaking. Writing about the growth of biotechnologies that are forged on "the political economy of hope" (16; cited in 17), researchers have shown how the biomedical market capitalises on social anxieties to forge a successful industry around the bodies of healthy people (18). While feminist studies have examined (19, 20) new reproductive technologies and their increased social and medical surveillance of women's bodies, aesthetic surgeries have often remained outside their analytical framework. However, Rodrigues' (21) call for serious engagement with the biopolitics of human genitalia is noteworthy. She adopts a Foucauldian framework (22) to argue that aesthetic surgeries involving the vagina (in particular, vaginoplasty and labiaplasty) mark a deployment of biopower to create what she calls an "optimal" vagina - one that is expected to be receptive both to reproduction and heteronormative erotica. Her critique should, however, be understood in the context of popular Western discourse on aesthetic "enhancement/function", where vulval utility and appearance are associated with idealised visions of femininity. She shows how in the West, the genital cosmetic industry defines women's bodies in terms of "excesses" ("excess" tissue and skin in the cases of vaginoplasty and labiaplasty, respectively, and "excess" blood in menstrual hygiene discourse) that need corrective mechanisms to manage them to make them "acceptable". This process, she argues, ultimately "intensifies power relations by disciplining desire, producing subjects for desire as well as desiring subjects" (21: $p$ 789). Unsurprisingly, this clinical gaze of regulating the woman's body and bodily "excesses" finds social approvals in other patriarchal contexts as well.

Writing from Brazil, de Andrade (23) notes how body modification through cosmetic surgeries (including breast augmentation/reduction, liposuction, tummy tucking, rhinoplasty, and genital cosmetic surgeries) are on the rise; the women in her research sample had sought corrective "improvement" procedures after reportedly experiencing long periods of discontentment about their bodies. The author concluded that these women used body modification as a means of expression and viewed cosmetic surgery as "psychotherapy by scalpel" (23: p 78).

Indeed, several studies echo this paradox of women's autonomy and rights over their own bodies on the one hand, and the pathology or sexual disutility associated with perceived body/genital "abnormalities" on the other. Wild and colleagues' (24) pilot study on hymen reconstruction surgeries in Tunisia exemplifies this dilemma. They found that in a deeply entrenched patriarchal system that equates an intact hymen and blood on bed sheetsii with virginity (a requirement for arranged marriages), women use technology (such as the hymen reconstruction surgery) to pragmatically realise their personal aims of marriage and motherhood or overcoming past violent sexual experiences. According to the authors, these women were "both victims and agents: they cannot realistically hope to be completely free of coercive patriarchal attempts to control their bodies, but they may resist such attempts by seeking hymen reconstruction" (24: p $60)$.

The view that hymen reconstruction surgery or hymenoplasty, as it is more commonly known, is a pragmatic form of resistance is steadily gaining ground in literature from the Middle East. For example, anthropologists working in Iran (25, 26) have shown how women navigated the virginity industry by blurring the line between original and "fake" virginity (which is recreated through surgery), thereby potentially transforming the narrative through a resignification of gendered constructs of virginity and socially appropriate femininity. Whether hymenoplasty is a covert resistance tactic through which women unwittingly challenge hegemonic discourses mandating female premarital virginity or whether it is a process of reinforcing patriarchal expectations remains inconclusive. What is clear from the preceding review is the persistent medical and cultural pathologisation of women's genitalia and sexuality (27). How does this paradox influence both women and physicians involved in this production of desirable subjects? I attempt to examine this question through a qualitative interview-based pilot study conducted in three Indian cities.

\section{The pilot study: Data and method}

Although I originally intended to capture the "voices" of the clients (female patients who have either undergone or are contemplating undergoing the procedure), I could only gain access to aesthetic surgeons (more commonly known as plastic surgeons in India) in Ahmedabad, Delhi, and Bangalore. Physicians thwarted my interest in interviewing patients, citing client confidentiality. Although this may seem an unusual medical practice, previous studies (23) have similarly noted how doctors act as "an emphatic companion, as a friend, psychologist and therapist, in a way" ( $p$ 81) - they perpetuate a relationship built on a socially abhorrent secret. The choice of cities was governed by availability of both (1) a 
thriving cosmetic surgery industry, and (2) willingness of surgeons to agree on the interviews. Indeed, the cities of New Delhi, Ahmedabad and Bangalore are marked by upmarket middle-class consumer practices that allow the relative anonymity of busy cosmopolitan urban spaces. Given the clandestine nature of these "treatments", it was important to choose sites carefully. I interviewed three aesthetic surgeons in New Delhi and the National Capital Region (NCR), two in the north-west city of Ahmedabad, and two in the southern city of Bangalore.

The study was funded by the Population Foundation of India in New Delhi, a national non-governmental organisation (NGO) that works on research and advocacy of gender-based health interventions/programmes. The Institutional Ethics Committee of the Indian Institute of Technology, Gandhinagar (the organisation that I was associated with when I conducted this research) provided ethical approval for this study.

Surgeons were recruited based on an online search of news articles, advertisements, and promotional materials for female genital procedures in India. In some cases, I also approached treatment facilities through their social media profiles. Although cosmetic procedures are also offered in government hospitals in India, private clinics dominate the scene (28: Times of India, September 6, 2016). iii Hence, all my interviews were with doctors who practised in either large private hospitals or their own private clinics. These surgeons also offered other cosmetic procedures, including liposuction, abdominoplasty, breast reduction/augmentation, and a range of female genital aesthetic surgeries, such as vaginal tightening, vaginal rejuvenation, and labiaplasty.

Interviews with physicians were conducted in their work places (clinics/hospitals) in Hindi and English over a period of five weeks during January-February 2019. Before the start of each interview, I gave the surgeons a consent form that provided a description of the study. My semi-structured interview instrument included open-ended questions about the socio-demographic information (e.g., gender, age, marital status, and professional/educational background of the client-patients, wherever applicable); the patients' motivations to undergo these procedures (specifically, if the patient had indicated that it was her 'choice' to seek hymenoplasty to avoid any potential sexual embarrassment or if she had been advised/forced by any other family member); questions about parental approval (as discussed in the opening section, parental approval is crucial to the social legitimacy of a romantic union, especially in arranged marriages); and the perceptions of surgeons (their rationale for hymenoplasty, their policies on post-operative care, and the medical ethics around these procedures).

The surgeons were initially reticent about their experiences with conducting such procedures, although they unanimously stated that such procedures are neither unethical nor illegal. For the most part, they were unable to provide a ballpark estimate of the number of reconstructive surgeries they had performed annually, as they maintained no patient records to ensure confidentiality. They reported that those seeking hymenoplasty typically come with either their mothers or another adult female companion, highlighting the importance of parental as well as peer approvals of these processes. In most clinics where I conducted interviews, a hymenoplasty cost between INR 30,000-50,000 (approximately USD 432-720).
Given the short duration of the pilot study and the extremely sensitive nature of the procedures, I was only able to interview men surgeons. Women plastic surgeons (although rare) refused to talk to me about their experiences once they found out that my interviews were going to be about hymenoplasty and other female aesthetic surgeries. This was surprising as I had anticipated some degree of suspicion (26) and resistance from men rather than women doctors, given my status as a female researcher in a sexually repressed culture. I interpret the reluctance of women surgeons as indicative of a more morally ambivalent position that ultimately reproduces repressive norms around women's sexual rights. These caveats (which limited the scope of the interview data) notwithstanding, the interviews with surgeons offered insights that motivated a sociological interrogation of a secretive and highly under-studied topic.

In what follows, I build on sociological scholarship on the middle class in India to argue how the intersecting logics of market and consumption have come to dominate cultures around the body and sexuality. Additionally, I reflect on the bio-moral role of surgeons in offering hymenoplasty, a controversial procedure. I conclude with a call for more research to understand the social and public health implications of the burgeoning cosmetic surgery industry.

\section{Findings \\ The "good life": bodies in the making}

While driving through any big Indian city, one can see flashy billboards inviting women (and men) to tauten, enhance, and modify their body parts in a manner almost akin to how a multi-cuisine restaurant offers a delectable menu of choices. Along with the images of cheerful models with tautened bodies are marketing taglines proclaiming, "Cosmetic artistry for the beautiful you" or "Beautifying personality, enhancing confidence... we make beautiful people", forming an easy association between a beautiful body (one that is free of excesses) and professional success. In a way, these ads orchestrate the neoliberal mantra where feeling and looking good is intimately tied to personal success and by that extension, personal responsibility - the making of a good biocitizen. Unsurprisingly, media reports on these new lifestyle choices abound. ${ }^{\text {iv }}$ Further, the websites of certain private clinics offering aesthetic surgeries have carefully curated images and testimonials that make body modification practices seem like a foundational experience for a cosmopolitan lifestyle.

The clinics that I visited were adorned with certificates and awards of physicians working there as well as patient testimonials evoking enormous optimism about surgical procedures that help realise cosmopolitan aspirations. An English-speaking receptionist would hand me glossy brochures and guide me to a waiting room with a modern décor, soothing meditative music, and scents reminiscent of relaxing lounges or spas. Clearly, the focus is on "feeling and looking good" (as the tagline on one brochure proudly announced); any indication that they were labs/clinics were erased turning them into ideal spaces for luxury consumption. Further, the fact that clinic staff and physicians spoke in English offers interesting fodder for sociological analysis. In interviews that largely took place in Hindi, physicians would occasionally use socially non-threatening English metaphors (for sexual intercourse), such as "thrill" or "union", in a studied attempt to avoid discussing taboo topics with a female 
researcher. Psychoanalyst Sudhir Kakar's (29) influential work on Indian sexuality, and Puri's (2) analysis of women and desire in postcolonial India, remind us how English, as an international language as opposed to an Indian one, allows educated Indians to discuss forbidden matters. However, as Kakar notes, these "euphemisms carry strong affective charge" (29: p 20). Puri (2) complicates this intricate process of negotiating the politics of sexuality by noting our inability to "name the discourse of sexuality in Hindi... [while] English eases the narratives on sexuality but also constrains them"; ( 2 : p 131). This cultural authority of the English language, which normalises and restricts narratives around sex and sexuality, was apparent in my interviews with the physicians.

Authors writing on India's new middle class and tracing the process of cultural globalisation (30) have previously noted how the "feel good factor" (31) acted as a catch-all for the sentiments of a growing (affluent) middle class engaged in the production of a distinctive, consumerist lifestyle. Interestingly, cognate terms such as "world-class", "(Indian) dream", and "unbound", which were used to evoke a new vision for India following economic liberalisation, were reproduced in glossy brochures advertising aesthetic surgeries, which invited clients to consider a range of unrestricted options for body modification and aesthetic genital surgeries. Significantly, these brochures emphasised the autonomous selfhood of the client-patient and their power to make choices.

In an insightful analysis of bridal magazines (particularly Bride \& Home) in post-liberalised India, sociologist Patricia Uberoi (12) similarly noted how these niche magazines offer tips to improve the bride's self-presentation, makeup, diet, skin care, exercise, and weight loss regimen in the "staging of a socially notable wedding" (12: p 235). She adds how the "editorial [of $\mathrm{B} \& \mathrm{H}]$ is explicitly framed in the neoliberal vocabulary of choice" (12: p 240), in which "modern" notions of freedom to choose from a range of consumer lifestyles is fused with the self-conscious choice of portraying oneself as "traditional"; therefore, patrilocality remains unchallenged, and the bride's "adjustment" to her new home and in-laws is prized. Likewise, the construction of women as purportedly autonomous agents in choosing to undergo hymenoplasty and other genital aesthetic procedures abound in promotional brochures, clinic websites, and in physicians' narratives (discussed more in the last section of this paper).

\section{Markets and moral consumption}

Social anthropologists $(8,31,32)$ examining change through the lens of urban lifestyles and spaces have noted how the consumer market is a potent site where pleasures, anxieties, and fears find sociologically rich articulations. Srivastava's $(7,8)$ use of the term "moral consumption" (7: p 341) serves to understand the tension between social norms and the seductive promise of consumerism-led modernity. In his discussion of new urban leisure spaces such as upper middleclass gated residential enclaves and Hindu temple complexes ${ }^{\vee}$ that combine hyper-consumerism, norms, and religiosity, Srivastava (7) describes the making of moral consumption (or a moral middle class) "where the active participation in consumerism is accompanied by an anxiety about it and its relationship to 'Indianness'" (7: p 134). In these new forms of (upper) middle-class consumption, Srivastava adds, "women can be both the guardians of tradition and take part in the sexualized presentations of the self, rather than having to choose between the two" (emphasis added; p 135). This observation finds resonance with female client-patients who reportedly choose self-surveillance and self-diagnose their non-virginal state, which they see as a "problem" that needs to be managed by cosmetic surgical interventions.

Social-moral anxieties around the hymen (or the vagina) are paramount to the success and growth of female genital aesthetic surgeries. Similar to Srivastava's (8) analysis of moral consumerism, wherein women take active part in consumerism but "can return home to "tradition" when required' ( $p$ 136), I argue that the (putative) freedoms cosmetic surgery grants women makes them loyal "glocal"(33) consumers who are self-consciously both "modern" and traditional. It ultimately makes pleasure, as Rodrigues (21) forcefully argues, a "biopolitical burden", and the cosmetic industry, a regulatory vehicle, disciplines female sexuality to conform with patriarchal notions of women's respectability and honour.

Noteworthy in these interpretations of middle-class consumption is William Mazzarella's (32) notion of "progress through pleasure" - the potential of aspirational consumption to transform vice into virtue. He makes his point using the advertising and marketing of a premium brand of condoms, Kama Sutra, as an illustration. In this understanding, consumption is a morally loaded act; its goal "as pleasure is connected to a noble charitable cause, bound by values and good intentions" (31: p 262). As such, young women's motivations to liberate themselves from the "vice" of premarital coitus and present themselves as "virtuous", respectable (hymen-intact) subjects for desirable suitors reflect this transformation of pleasure into a (wifely) moral duty. Significantly, consumption becomes the trope that connects the notions of pleasure as privilege and duty. Brosius' (32) pointed reminder of the basic market rule for a commodity (in this case, virginity) to remain valuable is important both the producer and the buyer should know how to weave it into larger performative social scripts; only then, she asserts, "can a commodity become a status-marker andmaker" (32: p 264).

In the concluding section, I evaluate how healthcare professionals (as producers or suppliers of the virginity industry) justify these controversial surgical procedures in the age of consumption, distinction, and morality.

\section{Conclusion: Negotiating dharma and desire}

The title of this section is inspired by the work of noted sociologist, Patricia Uberoi's (14) work on family and popular culture in India. While Uberoi used this phrase in the context of examining the tensions embedded in preserving the "moral economy" of the joint family in India, I find its two conceptual oppositions, dharma (a normative Hindu meaning of social duty) and desire, useful for summarising the contradictions in the modern romantic love complex. As discussed earlier, allegiance to social duty or dharma (in presenting oneself as virginal or improving the erotic utility of heterosexual conjugality) governs women's choices to undergo hymenoplasty and other female genital aesthetic surgeries. In contrast, desire, on the surface, offers a free-fall, uninhibited space that ultimately produces gendered "deviant" bodies that need to be regulated. In other words, dharma disciplines desire.

During interviews, physicians invoked the trope of dharma (as in medical duty) to explain their morally ambivalent position. In a culture with deeply rooted patriarchal norms with no 
clear medical guidelines or regulatory framework governing the cosmetic surgery industry, aesthetic surgeons' responses to these controversial procedures remain ambivalent at best. I was particularly curious to understand how cosmetic surgeons viewed these procedures and their social role while accepting requests to perform aesthetic genital procedures on the otherwise healthy bodies of young women. What emerged fairly consistently was that surgeons used terms like "medical duty" and "patient rights" to reconcile their moral unease. All the surgeons I interviewed attempted to portray themselves as empathetic medical companions for their client-patients citing "medical duty" and their inability to refuse treatment.

The idea of "medical duty", seems contrived since it is not uncommon for those same clinics to offer "special packages" (including discounted treatments and a two-night hotel stay for the patient) to young women before wedding season commences in October every year. Similarly, the social media pages of certain private clinics routinely offer special, discounted rates for body modification and genital surgeries (targeting both women and men) before highly commercialised annual socio-religious (Hindu) festivals such as Diwali, Navratri, and Karva Chauth. Clearly, de Andrade's (23) assertion that medical ethics bends to the logic of the market finds resonance in this study as well.

It is worth noting that physicians also justified performing these controversial procedures as their medical duty to respect patient autonomy, freedom, and empowerment. While the gender politics angle is immediately apparent, the simultaneous process of delimiting female sexual expression remains unsaid. This superficial co-opting of feminist language related to choice and rights has been noted in previous studies that reported physicians' responses $(21,34)$. Braun (37) notes that while patient autonomy makes for a convincing ethical justification for surgeons, the marketing strategies that are adopted often have a coercive influence on already vulnerable women. She adds that given that social control is routed through advertising and media, the notion of "free choice" is culturally circumscribed. In cosmetic surgery, medical ethics occupies a contentious position as free choice and agency are considered the pivotal tenets of this process. As Goldstein and Goldstein (39) point out, the "debate" invokes three biomedical ethical principles: autonomy (of the patient), non-maleficence (no harm), beneficence, and justice (for the individual and society as a whole). These principles, although not articulated as in the scholarship, were persistently invoked by the surgeons that I interviewed; they found themselves with no other option than to respond to the desires of female agency in matters of sexual autonomy. As one surgeon explained, referring to a past patient-client,

That young girl had come alone and cried a lot to get hymenoplasty done. She was a working woman. She said that she didn't need to take anyone's permission to do this. She stayed for two days at my clinic and resumed work on day three. It was that simple!

Clearly, the surgeons believed that responding to such requests was part of their medical duty to support young women as autonomous subjects making positive choices about their bodies. Admittedly, it was a studied denial to acknowledge that choice and agency are circumscribed in a web of medicalised coercion that is cloaked in the language of sexual autonomy, respectability, and social honour. Finally, another dimension of this process is the naturalising of the risks associated with these procedures. Surgeons also tend to gloss over the risks by emphasising the ordinariness of the procedure (very simple, as described by all the surgeons that I spoke). This is an important concern that has ethical implications. As Liao and colleagues (40) note, in cases where reliable information on risks and benefits is unavailable, the notion of informed consent is vastly compromised.

The ethical imperative given these economic and social forces, Sullivan (38) argues, "is to interrogate 'social imaginaries' - the perceptual schemas that constitute embodied subjects and their affective investments in ways that incite and then discriminate against particular bodies and bodily practices" (38: p 397). Ultimately, I argue that in this neoliberal framing of a modern, autonomous woman, the language of duty, market, and "care of the self" is used to control bodies, as Brosius (31) puts it, fetishise them "for a more private gaze (of the husband)" (31: p 321). In Mazzarella's (32) view, the (female) consumer in this new economy of pleasure has travelled full circle to a place where pleasure dominates sacrifice as self-fulfilment (32: p 101) - a virtuous self is made through technology and the market.

So, how do we make sense of and address this tacit complicity of surgeons who justify their actions using the allencompassing excuse of "medical duty" in the age of neoliberal consumerism? Wild and colleagues' (24) recommendation is straightforward but pointed. They argue that medical duty should also include physicians providing (a) appropriate medical information to patients about sexual and reproductive health so that they are able to recognise that "cultural beliefs about virginity are biologically false and misleading" (p. 60) and (b) a counselling-based empowerment approach that educates women about their options. The authors are, however, cautious in their recommendations, as in many cases and cultural contexts, virginity "certificates" or "rules" persist, and women turn to hymenoplasty as necessary recourse $(35,24)$ in the face of violent forms of social disapproval of premarital sex.

Finally, I return to the question of how this intellectual inquiry shapes the sexual health of young people. I have, throughout this piece, shown the dangers of a growing private, cosmetic industry that profits from making bodies sites of capitalist consumption. Given our understanding that this new form of corporeal capitalism will only persist and grow, how do we make this industry safer for women and men? Thankfully, a few authors have paved the way. Marge Berer's (34) forceful call in her editorial piece for Reproductive Health Matters to shift our intellectual gaze from theorising to asking more policy-driven questions is refreshing. She directs our attention to what happens after these surgeries have been performed and ruminates on post-operative care, (altered) self-perception or body image, and the range of psychological effects on client-patients. Other authors echo similar sentiments. $(23,24)$. Additionally, as discussed earlier, the fact that medical ethics collides with commercially profitable medicalisation processes in the realm of cosmetic surgery needs to be acknowledged.

Patient autonomy, a critical dimension in medical ethics, needs to be revisited and redefined in an industry that reinforces oppressive cultural expectations of desirability and respectable femininity. Braun's (37) appeal to go past the dichotomy of responding to distressed patients either out of medical duty or genital liberation is significant: she notes that it is fruitful to look at female genital cosmetic surgeries as 
being both of these, simultaneously. That is, while a cosmetic surgery can potentially address the distress of a woman seeking treatment due to social pressures, the commercial pursuit of this intervention reinforces a medical model where women's genitalia are both in need of and fixable through surgery. This is deeply problematic as it demonstrates that the medical model of female genital cosmetic surgery is embedded in a moral-cultural framework that offers the possibility of body parts being upgraded, improved, and subjected to market forces.

More research to better understand the motivations and needs of both surgeons and patients is desirable in order to create effective policies around sexual health (36). Further, incorporating reproductive and sexual health education ${ }^{\text {vi }}$ in school curricula and public health communications (that breaks myths around the body and educates young people about the risks of medically unnecessary surgeries) can go a long way in rupturing established, coercively patriarchal environments.

Competing interests: None declared. This study was funded by a research grant (2018-2019) from the Population Foundation of India, New Delhi.

Acknowledgements: The author acknowledges the generous grant of PFI (New Delhi) that supported this study. Research assistance of Ms Arushi Sahay and Ms Swati Joshi is acknowledged.

\section{Notes}

See the Guttmacher-Lancet Report (44) for a detailed discussion on definitive advances and a renewed vision for SRHR (sexual and reproductive health and rights) interventions in the Global South.

iThis culture of presenting oneself as a virgin on the wedding night persists despite the fact that the hymen is not a reliable indicator of past sexual experience; studies have shown that some women may lack a hymen at birth or that the hymen can be torn for reasons other than coital behaviour, such as athletic activities and injurious falls (36). Still other studies have noted the shifting cultural definitions of virginity and that vaginal sexual penetration cannot be medically or informally ascertained (24)

iiiReconstructive surgeries in India are steadily becoming more popular, attracting both domestic and foreign clients $(45,46)$. While government hospitals and medical schools have accredited and trained reconstructive surgeons, cosmetic or aesthetic surgeries are primarily carried out in private hospitals. As Bhattacharya (28) notes, government institutions that have well trained and experienced practitioners think of these enhancement procedures as 'too frivolous a thing to indulge in, as much more noble deeds like treating burns and congenital abnormalities are always beckoning us' (p. 431)

ivSee, for example, media reporting on designer vaginas $(47,48,49)$. Furthermore, in 2012, a product called '18 Again' (50) was launched as a 'woman's empowerment product' aimed at 'rejuvenating and tightening' the vagina. The video advertisement featuring a woman and her husband shows the two prancing around on the patio of what seems to be a joint family household with a pair of bemused elderly onlookers (probably, one set of in-laws); it sends reassuring signals to advertisement viewers that marital sexual conjugality has been appropriately domesticated.

vSrivastava's (8) analysis of new urbanism in India and its consolidation through a consumerist society is organised around the cultural examination of Akshardham Temple in Delhi, owned by the Hindu Swaminarayan sect (a dominant transnational Hindu community), resembling, as Srivastava suggests, a 'religious theme park' whose design draws inspiration from the North American theme parks of Disneyland and Universal Studios. He adds how women visitors 'move seamlessly between playing consumers and devoutly religious persons precisely because the same space provides opportunities for both consumerism and religiosity' (7, 8: p. 135)

viWhile acknowledging the importance of sex education as part of school curricula, it is important to note that introducing sexuality education does not automatically translate into behavioural change. Studies remind us that unless educators are open and committed to emphasising the pleasure dimension of sexual experiences (41); positive sexual self-understanding and self-efficacy (42); and the critical role of the culture governing sexual ideals and norms (43), the effectiveness of sexuality education will remain stunted.

\section{References}

1. Ghanim D. The virginity trap in the Middle East. New York: Palgrave; 2015.

2. Puri J. Woman, body, desire in post-colonial India: Narratives of gender and sexuality. New York: Routledge; 1999.

3. Abraham L. Bhai-behen, true love, time-pass: Friendships and sexual partnerships among youth in an Indian metropolis. Cult Health Sex. 2002 Jan 1;4(3):337-353. Available from: https://doi.org/ 10.1080/13691050110120794.

4. Dickey S. The pleasures and anxieties of being in the middle: Emerging middle-class identities in urban South India. Mod Asian Stud. 2012 Aug 11;46(3):559-599. Available from: https://doi.org/ 10.1017/S0026749X11000333.

5. Bhandari P, Titzmann FM. Introduction. Family realities in South Asia: Adaptations and resilience. SAMAJ. 2017 Sep 14;16:1-12. Available from: https://doi.org/10.4000/samaj.4365.

6. Twamley K, Sidharth J. Negotiating respectability: Comparing the experiences of poor and middle-class young urban women in India. Mod Asian Stud. 2019 Sep;53(5):1646-1674. Available from: https:// doi.org/10.1017/S0026749X17000816

7. Srivastava S. Urban spaces, Disney-divinity and moral middle classes in Delhi. In: Bhaviskar A, Ray R, editors. Elite and everyman:The cultural politics of the Indian middle classes. Delhi: Routledge; 2011. p. 338-345

8. Srivastava S. New urbanism, post-nationalism and consumerist modernity in India. In: Kravets O, Maclaran P, Miles S, Venkatesh A, editors. The SAGE handbook of consumer culture. London: Sage; 2018. p. 124-142. Available from: http://dx.doi.org/ 10.4135/9781473998803.n8.

9. Ferguson L, Desai S. Sexual and reproductive health and rights for all:Translating the Guttmacher-Lancet Commission's global report to local action. Reprod Health Matters. 2018 Jul 3; 26(52):6-7. Available from: https://doi.org/10.1080/09688080.2018.1487621.

10. Kabra R, Ali M, Gulmezoglu A, Say L. Research capacity for sexual and reproductive health and rights. Bull World Health Organ. 2016 Jun 2;94:549-550. Available from: http://dx.doi.org/10.2471/BLT. 15.163261 .

11. Zuccala $E$, Horton R. Addressing the unfinished agenda on sexual and reproductive health and rights in the SDG era. Lancet. 2018 Jun 30;391(10140):2581-2583. Available from: https://doi.org/10.1016/ s0140-6736(18)30890-0.

12. Uberoi P. Aspirational weddings: The bridal magazine and the canons of 'decent marriage'. In: Jaffrelot C, Veer PV, editors. Patterns of middle class consumption in India and China. New Delhi: Sage; 2008. p. 230-262. Available from: http://dx.doi.org/ 10.4135/9788178299976.n12.

13. Donner H. Domestic goddesses: Maternity, globalization and middleclass identity in contemporary India. New Delhi: Routledge; 2008.

14. Uberoi P. Freedom and destiny: Gender, family and popular culture in India. New Delhi: Oxford University Press; 2006.

15. Phadke S. Some notes towards understanding the construction of midde-class urban women's sexuality in India. In: Misra G, Chandiramani R, editors. Sexuality, gender and rights: Exploring theory and practice in South and Southeast Asia. New Delhi: Sage; 2005. p.67-81

16. Novas C. The political economy of hope: Patients' organizations, science and biovalue. BioSocieties. 2006 Oct 25;1(3):289-305. Available from: https://doi.org/10.1017/S1745855206003024.

17. Nadimpally S, Raveendran A, Sivasubramanian P. Of body and biotechnology: A gendered interrogation. New Delhi: Sama Resource Group for Women and Health; 2017.

18. Subramaniam B. Colonial legacies, postcolonial biologies: Gender and the promises of biotechnology. Asian Biotechnol Dev Rev. 2015 
Mar 1;17(1):15-36.

19. Unnithan M. Infertility and assisted reproductive technologies (ARTs) in a globalising India: Ethics, medicalisation and agency. Asian Bioeth Rev. 2010 Mar 19;2(1):3-18.

20. Nadimpally S, Marwah V, Shenoi A. Globalisation of birth markets: A case study of assisted reproductive technologies in India. Glob Health. 2011 Aug 12;7(1):27. Available from: https:// globalizationandhealth.biomedcentral.com/articles/10.1186/17448603-7-27.

21. Rodrigues $S$. From vaginal exception to exceptional vagina:The biopolitics of female genital cosmetic surgery. Sexualities. 2012 Dec 12;15(7):778-794. Available from: https://doi.org/ $10.1177 \% 2 F 1363460712454073$.

22. Foucault M. The history of sexuality. Volume 1: An introduction. New York:Vintage Books; 1990.

23. de Andrade DD. On norms and bodies: Findings from field research on cosmetic surgery in Rio de Janeiro, Brazil. Reprod Health Matters. 2010 Jun 10;18(35):74-83. Available from: https://doi.org/10.1016/ S0968-8080(10)35519-4.

24. Wild V, Poulin H, McDougall CW, Stockl A, Biller-Andorno N. Hymen reconstruction as pragmatic empowerment? Results of a qualitative study from Tunisia. Soc Sci Med. 2015 Dec 1;147:54-61. Available from: https://doi.org/10.1016/j.socscimed.2015.10.051.

25. Kaivanara M. Virginity dilemma: Re-creating virginity through hymenoplasty in Iran. Cult Health Sex. 2015 Aug 12;18(1):71-83. Available from: https://doi.org/10.1080/13691058.2015.1060532.

26. Ahmadi A. Recreating virginity in Iran: Hymenoplasty as a form of resistance. Med Anthropol Q. 2016 Jun;30(2):222-237. Available from: https://doi.org/10.1111/maq.12202.

27. Davis SW. Loose lips sink ships. Feminist Studies. 2002 Apr 1;28(1):735. Available from: https://doi.org/10.2307/3178492.

28. Bhattacharya S. Teach aesthetic plastic surgery in medical colleges. Indian J Plast Surg. 2012 Sep;45(3):431-432. Available from: https:// doi.org/10.4103/0970-0358.105932.

29. Kakar S. Intimate relations: Exploring Indian sexuality. New Delhi: Penguin India; 2000.

30. Fernandes L. India's new middle class: Democratic politics in an era of economic reform. Minnesota: University of Minnesota Press; 2006.

31. Brosius C. India's middle class: New forms of urban leisure, consumption and prosperity. New Delhi: Routledge India; 2010.

32. Mazzarella W. Shoveling smoke: Advertising and globalization in contemporary India. Durham \& London: Duke University Press; 2003.

33. Robertson R. Glocalization:Time-space and homogeneityheterogeneity. In: Featherstone M, Lash S, Robertson R, editors. Global modernities. London: SAGE; 1995. p. 25-44.

34. Berer M. Cosmetic surgery, body image and sexuality. Reprod Health Matters. 2010 Jun 10;18(35):4-10. Available from: https://doi.org/ 10.1016/S0968-8080(10)35518-2.

35. Lock M, Kaufert P, Harwood A. Pragmatic women \& body politics. New York: Cambridge University Press; 1990.

36. Essén B, Blomkvist A, Helstrom L, Johnsdotter S. The experience and responses of Swedish health professionals to patients requesting virginity restoration (hymen repair). Reprod Health Matters. 2010 Jun
10;18(35):38-46. Available from: https://doi.org/10.1016/S09688080(10)35498-X.

37. Braun V. Female genital cosmetic surgery: A critical review of current knowledge and contemporary debates.J Women's Health. 2010;19(7): 1393-1407 https://doi.org/10.1089/jwh.2009.1728.

38. Sullivan N.'The price to pay for our common good': Genital modification and the somatechnologies of cultural (in)difference. Soc Semiot. 2007;17(3):395-409. Available from: https://doi.org/ 10.1080/10350330701448736.

39. Berman J. Cosmetic labiaplasty: The great ethical debate [Internet]. Berman Sexual Health Website. 2007 Jan. Available at: https:// bermansexualhealth.com/cosmetic-labiaplasty-the-great-ethicaldebate/.

40. Liao L-M, Michala L, Creighton SM. Labial surgery for well women: A review of literature. BJOG. 2009;117(1). Available from: https://doi.org/ 10.1111/j.1471-0528.2009.02426.x.

41. Dailey DM.The failure of sexuality education: Meeting the challenges of behavioural change in a sex-positive context. $J$ Psychol Human Sex. 2008;9(3-4):87-97. Available from: https://doi.org/10.1300/ j056v09n03_05.

42. Raymond NM, Hutchinson AN. A pilot test of the effectiveness of an integrated sex positive education program. Am J Sex Educ. 2019;14(3): 315-341. Available from: https://doi.org/ 10.1080/15546128.2019.1584870.

43. Browes NC. Comprehensive sexuality education, culture and gender: The effect of the cultural setting on a sexuality education programme in Ethiopia. Sex Education: Sexuality, Society and Learning. 2015;15(6): 655-670. Available from: https://doi.org/ 10.1080/14681811.2015.1065476.

44. Starrs AM, Ezeh AC, Barker G, Basu A, Bertrand JT, Blum R, et al. Accelerate progress-sexual and reproductive health and rights for all: Report of the Guttmacher-Lancet Commission. Lancet. 2018 May 9;391(10140):2542-2692. Available from: https://doi.org/10.1016/ S0140-6736(18)30293-9.

45. Mishra A. India ranks 4th on list of plastic surgery hotspots. Times of India. 2016 Sep 6. Available from: https://timesofindia.indiatimes.com/ city/pune/India-ranks-4th-on-list-of-plastic-surgery-hotspots/ articleshow/54023206.cms.

46. Press Trust of India. Plastic surgery: India ranks 4 in world, attracts foreigners. Business Standard. 2013 Jan 21. Available from: https:// www.business-standard.com/article/beyond-business/plasticsurgery-india-ranks-4-in-world-attracts-foreigners110081100126_1.html.

47. Vora P. In sex-shy India, more women now want designer vaginas. Quartz India. 2017 Jan 3. Available from: https://qz.com/india/876494/ in-sex-shy-india-more-women-now-want-designer-vaginas/.

48. TNN.Women going under knife to restore virginity. Times of India. $2010 \mathrm{Apr} 15$. Available from: https://timesofindia.indiatimes.com/lifestyle/beauty/Women-going-under-knife-to-restore-virginity/ articleshow/5715442.cms.

49. India Today. What's on the menu? Who's going under the knife and why. India Today. 2012 Apr 30.

50. 18again.com [Internet]. Available from: http://www.18again.com/. 